\title{
Design of D-STATCOM for Power Quality Improvement in Wind Power Systems
}

\author{
Kapil Kumar Badoliya ${ }^{1}$, Rakesh Singh Lodhi ${ }^{2}$ \\ Oriental University, Indore, Madhya Pradesh India, 453555 \\ Corresponding author, E-mail address: kapilbadoliya@gmail.com ${ }^{1}$, rakeshlodhigs@ gmail.com² \\ Received Nov'23, 2019; received in revised form Jan'06, 2020; Accepted Jan' 23, 2020
}

\begin{abstract}
The study of problem is when high value reactive load adding or removing that time voltage sag and swell, we are trying to removing sag and swell we can say that stable for all time. The D-STATCOM ac current mode activities in active and reactive current are suppressed by mode shape; along these lines fortifying the receptive current exercises on the heap transport voltage guideline. It can be clearly seen from the obtained results that the voltage attains stability after a short surge even on sudden change in load conditions. The aforesaid conditions have been verified by both load addition and load removal. Application is all generation system used (wind, thermal, solar, etc.), D-STATCOM implement in wind power systems.
\end{abstract}

Keywords: Decoupling STATCOM, SAG, SWELL; Renewable energy; Wind Power Systems.

\section{Introduction}

Wind is renewable or non-conventional source of energy. This is clean, has no any effect of greenhouse on the atmosphere. Most important thing - it is a substitute of fossil fuels such as coal, oil or petroleum and natural gas etc. These are in limited quantity on earth and but primary source of producing electricity. Globally, $67 \%$ of electricity generated from fossil fuels, $13 \%$ from nuclear energy and rest of $20 \%$ from renewable energy source such as hydro energy, solar energy, wind energy, tidal energy etc. [9].

Wind energy systems can be classified based on location of system as onshore wind energy system and offshore wind energy system. Onshore systems are those located on land while Offshore are those which are away from the land i.e. located in sea or oceans. A part from classification based on location, further wind turbines are also classified based on their axis as vertical axis wind turbine and horizontal axis wind turbine. Vertical axis wind turbines are those whose axis is perpendicular with the direction of flow of wind while horizontal axis wind turbines are having their axis along with the direction of flow of wind. Classification can also be done based on nature of generator as IG and PMSG. Where, IG means Induction Generator and PMSG refers to Permanent Magnet Synchronous Generator.[21]

The fundamental target of this work is the design of a Decoupling STATCOM for improving the power quality of the electrical energy generated through wind turbines. It is a well-known fact that the use of conventional STATCOM can't increase the amount of active and reactive components of Power simultaneously. If one increases, the other decreases. The DSTATCOM is an 
effective technique to circumvent the same. Thus the primary objective of the proposed work is to attain power quality improvement using Decoupling STATCOM.

\section{Problem Identification}

This work proposes the MATLAB SIMULINK model of Decoupling STATCOM which is utilized for the improvement of intensity quality at circulation level. The serious Problems of this work are condensed as pursues:

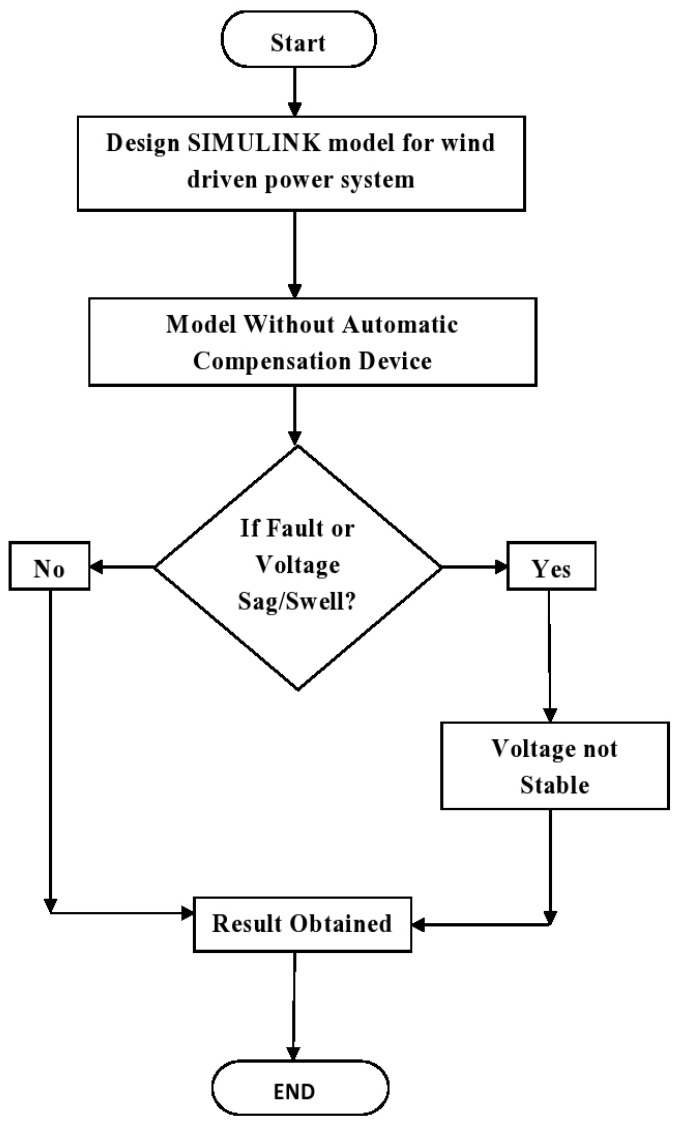

Fig.1 Flow Chart of Problem Identification

- To think about the model of Decoupled STATCOM alongside its controller.

- To investigate the performance of STATCOM using dqo transformation control scheme for different loads conditions like sudden reduction in load or sudden addition in load like wind turbine [1].

The sudden increase in load results in the drop in the voltage at the receiver terminal that is sag condition. similar sudden decrease in load results in the rise in the voltage at the receiver terminal that is swell condition.

When the design Simulink model for wind drive power system is run. Power is then generated by a self-excited induction generator (SEIG). But this model does not have any automatic compensation device. Even when the voltage in the fault condition or voltage sag / swell is not stable, the result is obtained and ends in the fault condition. This whole process flow chart figure is shown in Fig 1.

\section{Proposed Methodology \\ 3.1 Proposed Solution}

The block diagram shown in Figure 2 shows the wind turbine connected to the gear box SEIG system connected to the load via STL. Two types of loads are connected to the transmission line. The fix and variable load in which the variable load is added or removed according to the condition. A parallel D-STATCOM is fitted to the STL which is a voltage controlling device. When the design simulink model for wind drive power system is run. Power is then generated by a self-excited induction generator (SEIG). In which the fault or voltage sag / swell is monitored in the monitor voltage condition, this model also has an automatic compensation device DSTATCOM. When the voltage in the fault condition or voltage sag / swell is not stable, the result is stabilized and the D-STACOM voltage is terminated by obtaining the result. 
This whole process flow chart fig. Shown in 3.

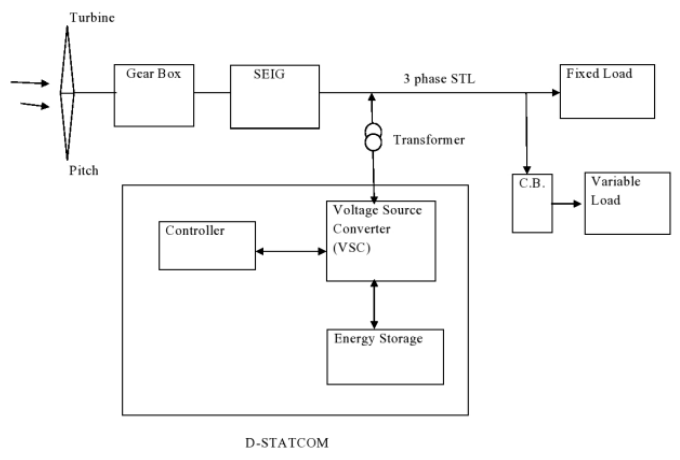

Fig.2 Block diagram of Decoupling STATCOM scheme under three-phase load variation

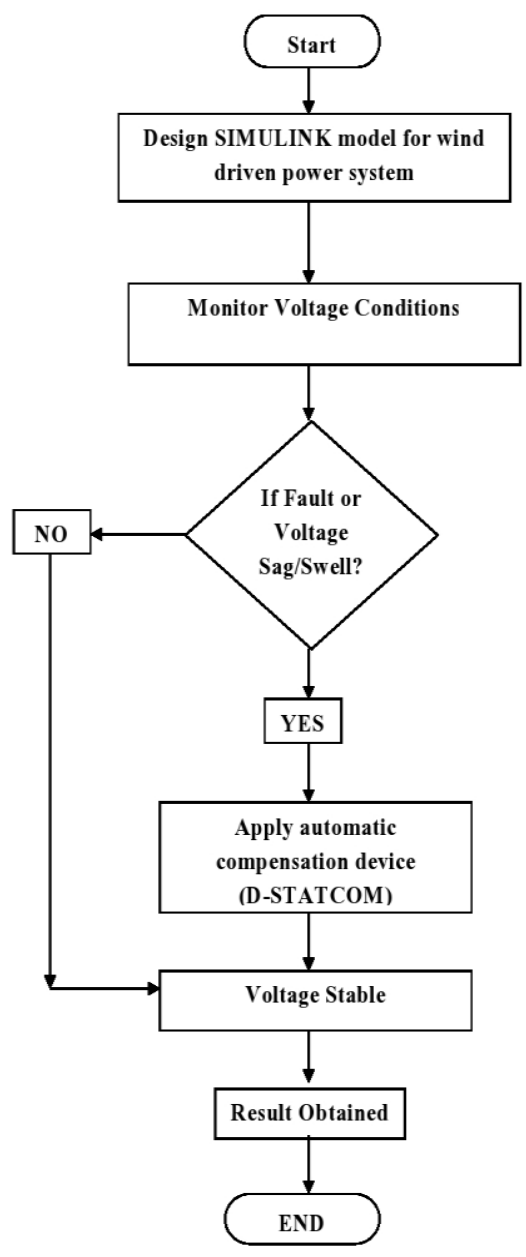

Fig 3 Flow Chart of proposed Solution

\subsection{D- STATCOM Model}

The three-stage STATCOM model can be depicted in per unit state-space structure as pursues:

$$
\begin{aligned}
& i_{d e}=-\frac{\omega_{s} r_{f}}{x_{f}} i_{d e}+\omega_{g} i_{q g}+\frac{\omega_{g}}{x_{f}}\left(v_{d L}-\right. \\
& \left.e_{d}\right) \\
& i_{q e}^{*}=-\frac{\omega_{s} r_{f}}{x_{f}} i_{q e}-\omega_{g} i_{d e}+\frac{\omega_{g}}{x_{f}}\left(v_{q L}-\right. \\
& \left.e_{q}\right)
\end{aligned}
$$

The per unit dc-side circuit condition is

$v_{d e}^{*}=\frac{1}{c_{d e}}\left(i_{d e}-\frac{v_{d c}}{r_{d c}}\right)$

where $(\mathrm{dc})$ is utilized to speak to the inverter exchanging misfortune. The immediate forces at the alternative current and dc sides of the VSI (Voltage Source Inverter) are equivalent, giving the accompanying force balance condition:

$v_{d c} i_{d c}=e_{d d} i_{d e}+e_{q} i_{q e}$

\subsubsection{Mathematical Formulation for Active and Reactive Power}

The values of prompt dynamic and receptive power, utilizing a coupling way to the STATCOM, at the heap can be given by:

$$
\begin{aligned}
& P_{e}=v_{d L} i_{d e}+v_{q L} i_{q e} \\
& Q_{e}=v_{q L} i_{d e}-v_{d L} i_{q e}
\end{aligned}
$$

Consider a synchronous reference outline where the d-axis is picked to harmonize with the heap transport voltage vector $\mathrm{V}_{\mathrm{L}}$. The above equations become:

$$
\begin{aligned}
& P_{e}=v_{d L} i_{d e} \\
& Q_{e}=-v_{d L} i_{q e}
\end{aligned}
$$

As Eq.7 and Eq.8 show, the d-axis current component $i_{\text {de }}$, represents the quick dynamic power and the q-hub current component $i_{\text {qe }}$, is the momentary receptive current. Therefore, STATCOM control configuration is rearranged, all things 
considered, with this reference outline on the grounds that the responsive power $\left(Q_{e}\right)$ control is only identified with the qhub current [1].

\subsubsection{Dynamic and Reactive Current} Control

Eq. 1 plainly shows that the STATCOM input current is prompted by its yield voltage balance. In this manner, even Eq.8 presumes that the receptive power can be legitimately controlled utilizing the responsive current the control coupling with the dynamic current still endures as a general rule. To get a decouple-like control for the receptive and dynamic current, Eq.1 and Eq. 2 can be changed as:

$$
\begin{aligned}
& i_{d e}=-\frac{\omega_{s} r_{f}}{x_{f}} i_{d e}+x_{d} \\
& i_{q e}=-\frac{\omega_{g} r_{f}}{x_{f}} i_{q e}+x_{q} \\
& x_{d}=\omega_{s} i_{q e}+\frac{\omega_{g}}{x_{f}}\left(v_{d L}-e_{d e}\right) \\
& x_{q}=-\omega_{s} i_{d e}-\frac{\omega_{g}}{x_{f}} e_{q}
\end{aligned}
$$

Equation 9 shows that an expanded dynamic current is actuated after the transient increment in $x_{d}$. This is likewise valid for the responsive current in Eq. 10. Based on these principles, the control actions and can be expressed as

$x_{d}=\left(K_{p 1}+\frac{K_{\text {in }}}{s}\right) \cdot\left(i_{d e}^{*}-i_{d e}\right) \ldots$.

$x_{q}=\left(K_{p 2}+\frac{K_{i z}}{s}\right) \cdot\left(i_{q e}^{*}-i_{q e}\right) \ldots$

Where Proportional-Integral regulators is used to control the STATCOM currents. When the control actions $\mathrm{x}_{\mathrm{d}}$ and $\mathrm{x}_{\mathrm{q}}$ are resolved, the STATCOM yield voltage command dse $e_{\mathrm{d}}^{*}$ an $\mathrm{de}_{\mathrm{q}}^{*}$ in Eq.11 and Eq.12 can be revised as:

The fundamental control structure for the STATCOM is point by point in Fig.4 Since STATCOM control depends on the VSI plot, the STATCOM yield voltage directions can be modified by goodness of Eq. 15 and Eq.16.

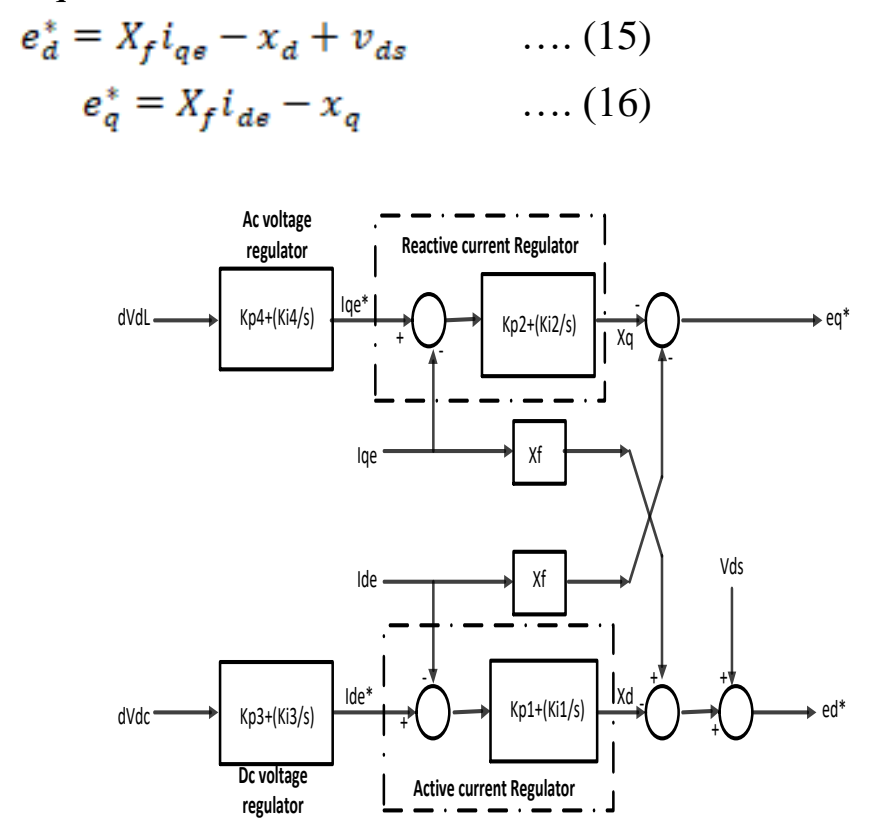

Fig. 4 Basic Control Scheme of STATCOM

Moreover, from the way that Eq.17 and Eq.18 tell the STATCOM dynamic and receptive power control separated from the STATCOM flows ( $\mathrm{i}_{\mathrm{de}}$ and $\mathrm{i}_{\mathrm{qe}}$ ), the dynamic current command $\mathrm{di}_{\mathrm{de}}^{\mathrm{f}}$, representing the $\mathrm{dc}$ voltage guideline, can be created legitimately utilizing a PI controller with the dc-connect voltage deviation as the information [1].

\subsubsection{Design of the Model Decoupling STATCOM Controller}

The dynamic IG framework model above can be linearized around a working point 
which renders the accompanying state space

$$
\Delta y=C \cdot \Delta x
$$

model:

$\Delta x=A \cdot \Delta x+B \cdot \Delta u$

$$
\begin{aligned}
& \Delta x \\
& =\left[\begin{array}{llllllllllllll}
\Delta V_{d L} & \Delta V_{q L} & \Delta V_{d e} & \Delta i_{d e} & \Delta i_{q e} & \Delta \omega_{r}^{u} & \Delta \emptyset_{q s} & \Delta \emptyset_{q r} & \Delta \emptyset_{d s} & \Delta \emptyset_{d r} & \Delta i_{d T L} & \Delta i_{q T L} & \Delta i_{d L} & \Delta i_{q L}
\end{array}\right]^{T} \Delta y \\
& =\left[\begin{array}{llll}
\Delta V_{d L} & \Delta V_{d e} & \Delta i_{d e} & \Delta i_{q e}
\end{array}\right]^{T} \\
& \Delta u=\left[\begin{array}{ll}
\Delta e_{d} & \Delta e_{q}
\end{array}\right]^{T} \\
& K_{0} \\
& =\left[\begin{array}{cccccccccc}
0 & K_{p 1} K_{p 3} & K_{p 1} & P_{d} & 0 & K_{p 1} K_{i 3}+K_{p 3} K_{i 1} & K_{i 1} & 0 & 0 & K_{i 1} K_{i 3} \\
K_{p 2} K_{p 4} & 0 & -P_{q} & K_{p 2} & K_{p 2} K_{i 4}+K_{p 4} K_{i 2} & 0 & 0 & K_{i 2} & K_{i 2} K_{i 4} & 0
\end{array}\right] \\
& \Delta V_{d L} \quad \Delta V_{d e} \quad \Delta i_{d e} \quad \Delta i_{q e} \int \Delta i_{d e} d t \quad \int \Delta i_{q e} d t \quad \int \Delta V_{d L} d t \quad \int \Delta V_{d e} d t \quad \iint \Delta V_{d L} d t \quad \iint \Delta V_{d e} d t \\
& \Delta u=\left[\begin{array}{cccccccccc}
0 & K_{12} & K_{13} & K_{14} & 0 & K_{16} & K_{17} & 0 & 0 & K_{1,10} \\
K_{21} & 0 & K_{23} & K_{24} & K_{25} & 0 & 0 & K_{28} & K_{29} & 0
\end{array}\right] . \Delta y_{a}
\end{aligned}
$$

To orchestrate a mode decoupling STATCOM controller dependent on the physical control structure as appeared in Fig.5, six extra state variables: $\int \Delta \mathrm{v}_{\mathrm{dL}} \mathrm{dt}, \int \Delta \mathrm{v}_{\mathrm{dc}} \mathrm{dt}, \int \Delta \mathrm{i}_{\mathrm{de}} \mathrm{dt}$, $\int \Delta \mathrm{i}_{\mathrm{qe}} \mathrm{dt}, \iint \Delta \mathrm{v}_{\mathrm{dL}} \mathrm{dt}, \iint \Delta \mathrm{v}_{\mathrm{de}} \mathrm{dt}$, in this meant as $\Delta \mathrm{x}_{e}$, were made and converged into Eq. 17 and Eq.18 as another state vector $\Delta \mathrm{x}_{\mathrm{a}}$. We at that point have the expanded state space model as pursues:

$\Delta x_{a}=A_{a} \cdot \Delta x_{a}+B_{a} \cdot \Delta u$

$\Delta y_{a}=C_{a} \cdot \Delta x_{a}$

where,

The STATCOM yield voltage $\left(\Delta \mathrm{e}_{\mathrm{d}}\right.$ and $\Delta \mathrm{e}_{\mathrm{q}}$ ) of the expanded state space model in Eq. 21 and Eq.22 can be gotten from the physical control structure Fig. 5 in the structure as

$\Delta u=K_{0} \cdot \Delta y_{a}$
Here the yield input gains $\mathrm{K}_{0}$ It ought to be noted cross coupling gains $X_{f}$ in Fig.5 was supplanted by $P_{q}$ and $P_{d}$, individually. Depending upon the control gain location described in Eq.19, a constrained output feedback control $\Delta u$ was given by Eq.20 It is clear that the controller gains in Eq.20can be derived as compared to Eq.19 except for the mismatch at the entries $K_{12}$ and $K_{21}$.In order to circumvent this issue, two additional control loops, $F_{d}$ and $F_{q}$, (corresponding to states $\Delta \mathbf{v}_{\text {dc }}$ and $\Delta v_{d L}$ ) are included into the outputfeedback $\operatorname{control} \Delta u$ by letting $K_{12}=K_{p 1} \cdot K_{p 3}+F_{d}$ and $K_{21}=K_{p 2} \cdot K_{p 4}+F_{q}$, respectively.

An engineered control structure dependent on Eq. 19 and Eq. 20 is shown in Fig. 5. Plainly this control structure is not the same 
as that in Fig.5 are the feed forward increases $F_{d}$ and $F_{q}$. Because the physical current control circles are saved for the new control plot, zero relentless state mistakes for load transport voltage $\Delta \mathrm{v}_{\mathrm{dL}}$, dc-interface voltage $\Delta \mathrm{v}_{\mathrm{dc}}$, and STATCOM flows $\left(\Delta \mathrm{i}_{\mathrm{de}}\right.$ and $\Delta \mathrm{i}_{\mathrm{qe}}$ ) are achievable [1].

Decoupling STATCOMs can be categorized into three classes based on control structure. It helps in investigating the studied system by analyzing the dynamic response [1].

$$
\begin{aligned}
& e_{d}^{*}=X_{f} i_{q e}-x_{d}+v_{d s} \\
& e_{q}^{*}=X_{f} i_{d e}-x_{q}
\end{aligned}
$$

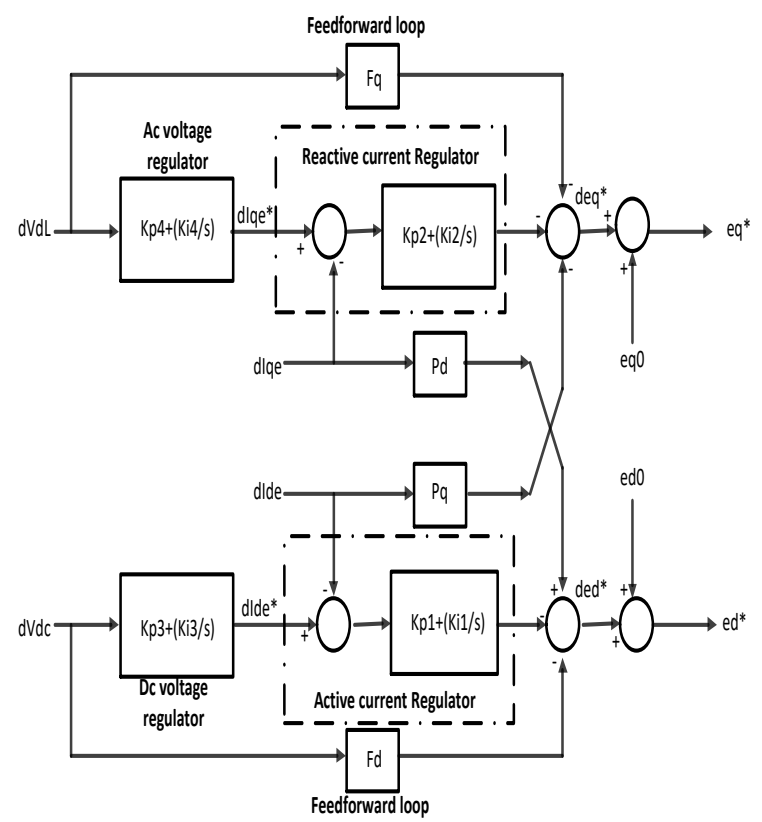

Fig.5 Design of Mode Decoupling STATCOM Controller

\section{MATLAB MODEL}

Per Unit system is adopted while simulating the proposed control scheme and model has been tested under varying load and fault conditions.

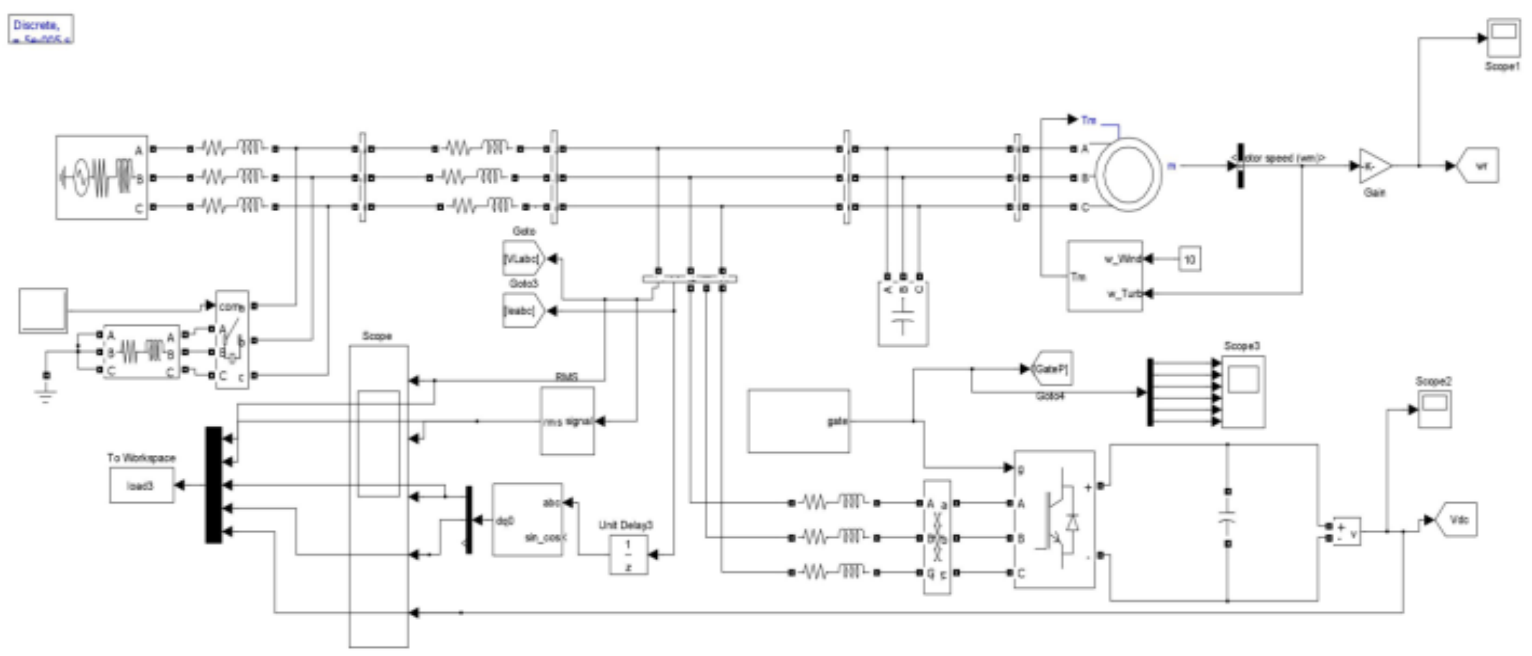

Fig.6 Simulink model of Decoupling STATCOM Scheme under Three-phase Load Variation 


\section{Results}

\section{Simulation Results of Transmission Line} With D-STATCOM At Linear Load (SL)

Depicts the effect of increase in load Demand on the SEIG D-STATCOM System without connecting D-STATCOM at PCC while Simulation Waveform shows the effectiveness of STATCOM for voltage regulation. The sudden increase in load results in the drop in the voltage at the receiver terminal that is sag condition.

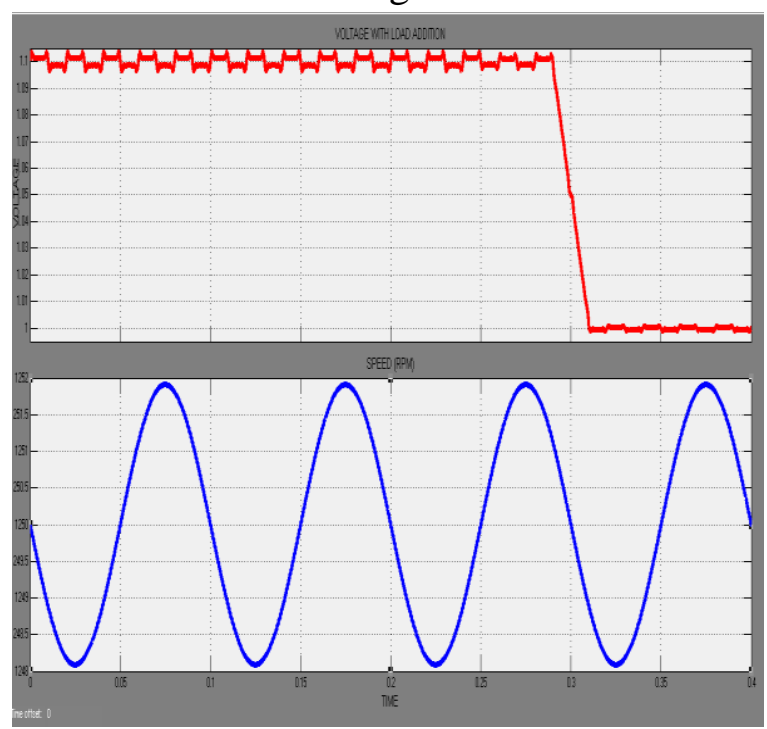

Fig.7 Simulink Result for System response on increase in load demand without D-STATCOM

This can be clearly seen from the Simulation Waveform that as the load is increased at the receiving end, the voltage drops. Without the use of the D-STATCOM, the voltage maintains a low level whereas the application of D-STACTCOM maintains the level of voltage to almost at a constant level even after the addition of the load thereby proving the fact that the controlling action is successful by the D-STATCOM that's control sag.

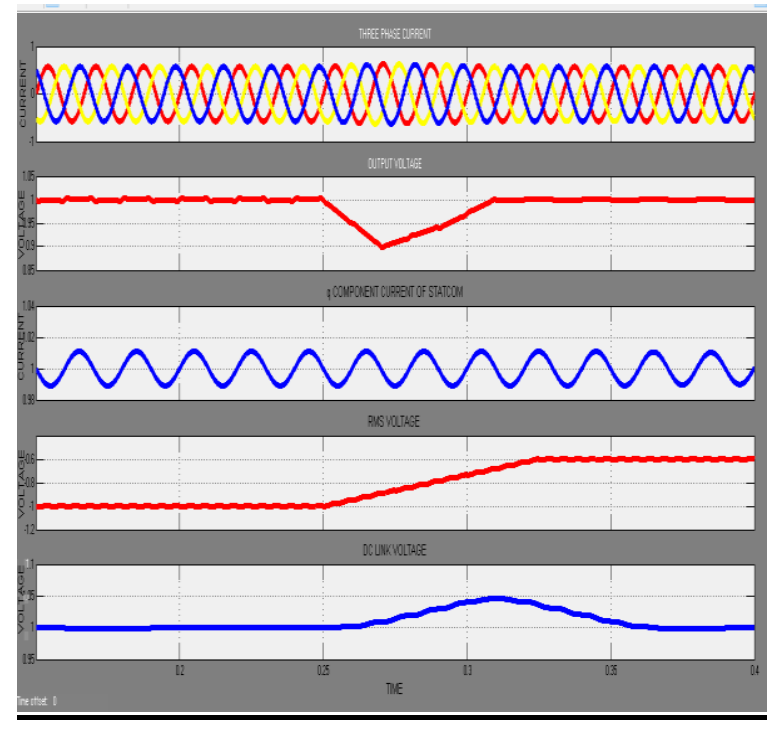

Fig.8 Simulink Result for System Response of SEIG-STATCOM System on increase in load demand with $D$ STATCOM

\section{B. Simulation Results of Transmission} Line With D-STATCOM At Linear Load (UL)

A similar analysis can be done for the sudden removal of the load Demand on the SEIG D-STATCOM System without connecting D-STATCOM at PCC while Simulation Waveform shows the effectiveness of STATCOM for voltage regulation. The sudden decrease in load results in the rise in the voltage at the receiver terminal that is swell condition. This can be clearly seen from the Simulation Waveform that as the load is decrease at the receiving end, the voltage rise. Without the use of the D-STATCOM, the voltage maintains a high level whereas the application of D-STACTCOM maintains the level of voltage to almost at a constant level even after the removable of the load thereby proving the fact that the controlling action is 
successful by the D-STATCOM that's control swell.

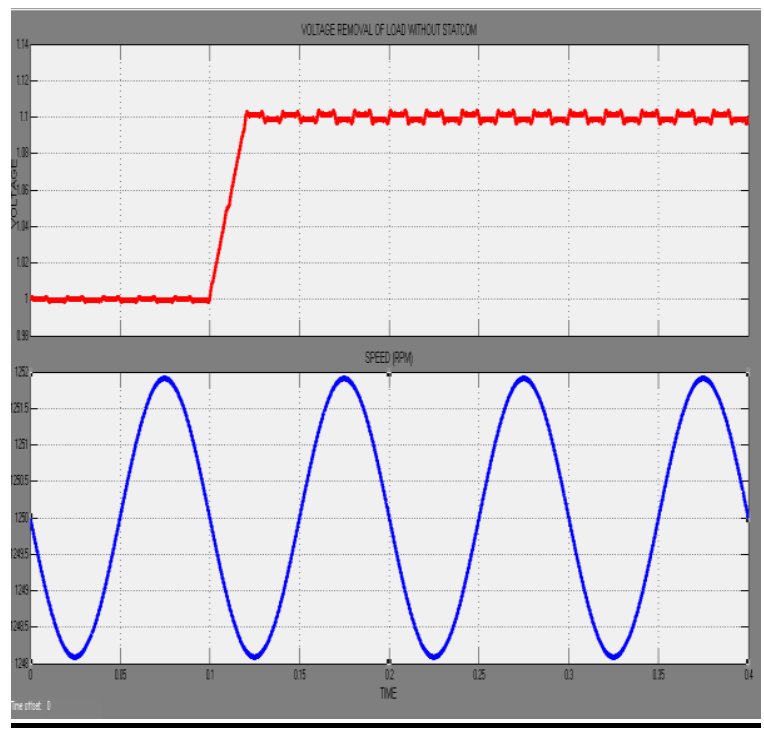

Fig.9 Simulink Result for System

Response on sudden removal of load without STATCOM

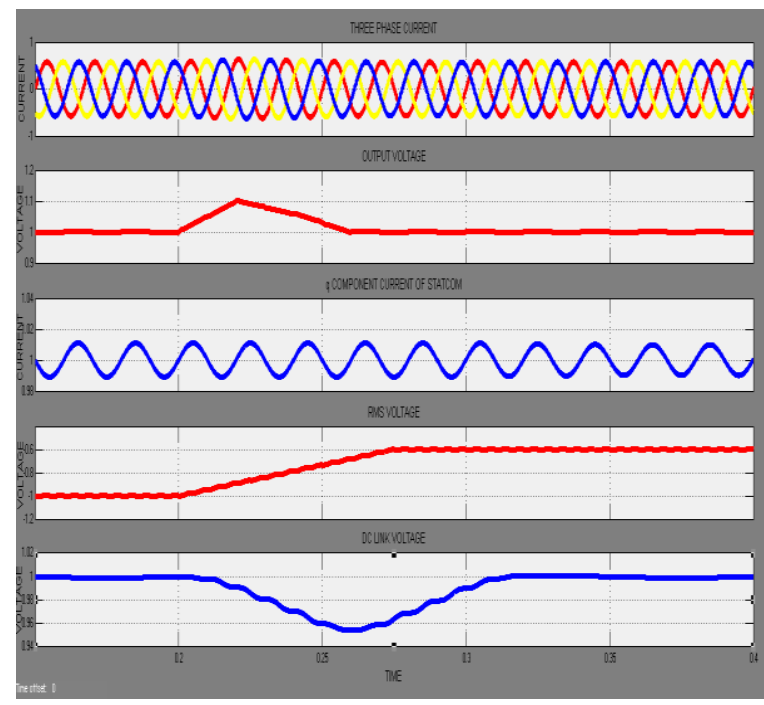

Fig.10 Simulink Result for System Response of SEIG-STATCOM System on sudden removal of load with STATCOM

\section{COMPARATIVE RESULT ANALYSIS}

\begin{tabular}{|l|l|l|l|l|}
\hline \multirow{4}{*}{$\begin{array}{l}\text { Without } \\
\text { D-STATCOM }\end{array}$} & \multicolumn{4}{|c|}{ Wind Speed 3000, Generation Voltage 3000 VA } \\
\cline { 2 - 5 } & Condition & $\begin{array}{c}\text { Voltage level } \\
\text { before }\end{array}$ & $\begin{array}{c}\text { Voltage level } \\
\text { after }\end{array}$ & Stable Time \\
\cline { 2 - 5 } & Addition of Load & $1.1 \mathrm{pu}$ & $1.0 \mathrm{pu}$ & Not Stable \\
\cline { 2 - 5 } & Removable of Load & $1.0 \mathrm{pu}$ & $1.1 \mathrm{pu}$ & Not Stable \\
\hline $\begin{array}{l}\text { With } \\
\text { D-STATCOM }\end{array}$ & Addition of Load & $1.1 \mathrm{pu}$ & $1.1 \mathrm{pu}$ & $0.25 \mathrm{~s}-0.32 \mathrm{~s}$ \\
\cline { 2 - 5 } & Removable of Load & $1.0 \mathrm{pu}$ & $1.0 \mathrm{pu}$ & $0.2 \mathrm{~s}-0.27 \mathrm{~s}$ \\
\hline
\end{tabular}

\section{Conclusion}

A common device that is widely used for this purpose is Static Compensator (STATCOM). Although STATCOM provide reasonable amount of regulation but still its performance is poor therefore, Concept of Mode decoupling came into existence which improves the performance of the STATCOM drastically. In addition to load bus voltage regulation, Mode decoupling STATCOM also stabilizes the rotor speed for SEIGSTATCOM wind conservation system. Improvement in electromechanical mode damping can be accomplished while deciding the mode state of the shut circle reactions. The STATCOM ac current mode activities in active and reactive current are suppressed by mode shape; along these lines fortifying the receptive current exercises on the heap 
transport voltage guideline. Zero-consistent state mistake guideline and improved transient journey can be accomplished by including $\int \Delta \mathrm{v}_{\mathrm{dL}} \mathrm{dt}, \int \Delta \mathrm{v}_{\mathrm{dc}} \mathrm{dt}, \int \Delta \mathrm{i}_{\mathrm{de}} \mathrm{dt}$, $\int \Delta \mathrm{i}_{\mathrm{qe}} \mathrm{dt}, \iint \Delta \mathrm{v}_{\mathrm{dL}} \mathrm{dt}, \iint \Delta \mathrm{v}_{\mathrm{de}} \mathrm{dt}$ variables into system dynamic model.

\begin{tabular}{|c|c|c|}
\hline $\begin{array}{l}\text { Induction } \\
\text { Machine }\end{array}$ & $\begin{array}{l}\text { D- } \\
\text { STATCOM }\end{array}$ & Load \\
\hline $\begin{array}{l}\text { 1.Voltage } \\
220 \text { Volt } \\
\text { 2.Current } \\
13 \mathrm{Amp} \\
\text { 3.Power } \\
\text { 3KVA }\end{array}$ & $\begin{array}{l}\text { 1. Bridge Arms } \\
3 \\
\text { 2.Power } \\
\text { Electronic } \\
\text { Device } \\
\text { IGBT/Diodes } \\
\text { 3.Snubber } \\
\text { Resistance } \\
\text { 5000 } \\
\text { ohms } \\
\text { 4.Series line } \\
\text { resistance } \\
\text { 0.0446 pu } \\
\text { 5.Series line } \\
\text { reactance } \\
\text { 0.8644 pu } \\
\text { 6.DC-Link } \\
\text { Capacitance } \\
6800 \mathrm{uF} \\
\text { 7.Switching } \\
\text { frequency } \\
\text { 1380 Hz }\end{array}$ & $\begin{array}{c}\text { 1.Voltage } \\
220 \\
\text { Volt } \\
\text { 2.Current } \\
13 \text { Amp } \\
\text { 3.Power } \\
2860 \\
\text { VA }\end{array}$ \\
\hline
\end{tabular}

\section{Conflict of interest}

The author declares no conflict of interest.

\section{References}

[1] Prasad, K. K., Myneni, H., \& Kumar, G. S. (2018). Power Quality Improvement and PV Power Injection by DSTATCOM With Variable DC Link Voltage Control from RSC-MLC. IEEE
Transactions on Sustainable Energy, 10(2), 876885.

[2] Nasiri, M. R., Farhangi, S., \& Rodríguez, J. (2018). Model predictive control of a multilevel CHB STATCOM in wind farm application using diophantine equations. IEEE Transactions on Industrial Electronics, 66(2), 1213-1223.

[3] Gupta, A. R., \& Kumar, A. (2019). Reactive power deployment and cost benefit analysis in DNO operated distribution electricity markets with D-STATCOM. Frontiers in Energy, 13(1), 86-98.

[4] Kerrouche, K. D. E., Wang, L., Mezouar, A., Boumediene, L., \& Van Den Bossche, A. (2019). Fractional-order sliding mode control for DSTATCOM connected wind farm based DFIG under voltage unbalanced. Arabian Journal for Science and Engineering, 44(3), 2265-2280.

[5] Choudhury, S., Bhowmik, P., \& Rout, P. K. (2018). Economic load sharing in a DSTATCOM integrated islanded microgrid based on fuzzy logic and seeker optimization approach. Sustainable cities and society, 37, 5769.

[6] Khoshooei, A., Moghani, J. S., Candela, I., \& Rodriguez, P. (2017). Control of D-STATCOM during unbalanced grid faults based on DC voltage oscillations and peak current limitations. IEEE Transactions on Industry Applications, 54(2), 1680-1690.

[7] Moghbel, M., Masoum, M. A., Fereidouni, A., \& Deilami, S. (2017). Optimal sizing, siting and operation of custom power devices with STATCOM and APLC functions for real-time reactive power and network voltage quality control of smart grid. IEEE Transactions on Smart Grid, 9(6), 5564-5575.

[8] Yuvaraja, T., Ramya, K., \& Gopinath, M. (2018). Meandering Vector Control Strategy as DSTATCOM in Renewable Cluster Grid for Power 
Optimization. Materials

Proceedings, 5(1), 1257-1263.

[9] Farivar, G., Townsend, C. D., Hredzak, B., Pou, J., \& Agelidis, V. G. (2016). Lowcapacitance cascaded H-bridge multilevel StatCom. IEEE Transactions on Power Electronics, 32(3), 1744-1754.

[10] Lu, D., Wang, J., Yao, J., Wang, S., Zhu, J., Hu, H., \& Zhang, L. (2017). Clustered voltage balancing mechanism and its control strategy for star-connected cascaded H-bridge STATCOM. IEEE Transactions on Industrial Electronics, 64(10), 7623-7633.

[11] Agarwal, R. K., Hussain, I., \& Singh, B. (2016). Implementation of LLMF control algorithm for three-phase grid-tied SPVDSTATCOM system. IEEE Transactions on Industrial Electronics, 64(9), 7414-7424.

[12] Sarvghadi, P., Ghazi, R., \& Heydaridoostabad, H. (2017, February). A new approach for predictive control system design to improve power factor and reduce harmonic current injection using D-STATCOM. In 2017 8th Power Electronics, Drive Systems \& Technologies Conference (PEDSTC) (pp. 401-406). IEEE.

[13] Wang, L., Lam, C. S., \& Wong, M. C. (2016). A hybrid-STATCOM with wide compensation range and low DC-link voltage. IEEE Transactions on Industrial Electronics, 63(6), 3333-3343.

[14] Abd-Elazim, S. M., \& Ali, E. S. (2016). Imperialist competitive algorithm for optimal STATCOM design in a multimachine power system. International Journal of Electrical Power \& Energy Systems, 76, 136-146.

[15] Amoozegar, D. (2016). DSTATCOM modelling for voltage stability with fuzzy logic PI current controller. International Journal of Electrical Power \& Energy Systems, 76, 129-135.
[16] Mishra, S., \& Ray, P. K. (2016). Power quality improvement using photovoltaic fed DSTATCOM based on JAYA optimization. IEEE Transactions on Sustainable Energy, 7(4), 16721680.

[17] Xu, R., Yu, Y., Yang, R., Wang, G., Xu, D., Li, B., \& Sui, S. (2014). A novel control method for transformerless H-bridge cascaded STATCOM with star configuration. IEEE Transactions on Power Electronics, 30(3), 11891202.

[18] Beza, M., \& Bongiorno, M. (2014). An adaptive power oscillation damping controller by STATCOM with energy storage. IEEE Transactions on Power Systems, 30(1), 484-493. [19] Tolabi, H. B., Ali, M. H., \& Rizwan, M. (2014). Simultaneous reconfiguration, optimal placement of DSTATCOM, and photovoltaic array in a distribution system based on fuzzyACO approach. IEEE Transactions on sustainable Energy, 6(1), 210-218.

[20] Badoni, M., Singh, A., \& Singh, B. (2015). Variable forgetting factor recursive least square control algorithm for DSTATCOM. IEEE Transactions on Power Delivery, 30(5), 23532361. 